\title{
UK extends the law to genetic engineering
}

From 1 August, 1978 any scientist intending to carry out experiments in genetic manipulation in the UK will be obliged by law to notify both the Genetic Manipulation Advisory Group (GMAG) and the Health and Safety Executive (HSE). Notification will be made very much as it is under the recent voluntary system, which has been operated by GMAG for the past year and a half and which has resulted in almost complete cooperation. Application of the new regulations should therefore be painless.

The new Genetic Manipulation Regulations have been made under the Health and Safety at Work Act. They arise directly from a recommendation of the Williams Working Party report of 1976 and were first drafted in August 1976. That draft, particularly in its provisional definition of genetic manipulation, was so criticised, if not ridiculed, that almost two years have been spent in wording the final regulations. Or, as John Dunster, deputy director general of the HSE, put it "Consultation is a very real process".

The final definition of genetic manipulation is said to have been widely approved and is in line with that accepted by the EEC and by several other countries. It reads: "the formation of new combinations of heritable material by the insertion of nucleic acid molecules produced by whatever means outside the cell, into any virus, bacterial plasmid, or other vector system so as to allow their incorporation into a host organism in which they do not naturally occur but in which they are capable of continued propagation".

The other stumbling block experienced by those drafting the regulations was how to define 'work'. The problem is that not all students consider it to be a four letter word; indeed some carry out research work and yet are not employed and consequently have not come under the Health and Safety at Work Act. The solution in the Genetic Manipulation Regulations has been to extend the meaning of work to encompass those who are "nonemployed' such as students.

The compulsion encoded in the regulations begins and ends with the notifi-

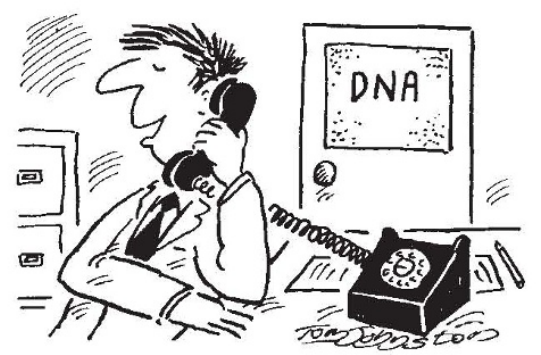

"I'm trying to cross a Health and Safety executive with a Genetic Manipulation adviser!" cation of both GMAG and the HSE of intention to carry out genetic manipulation. It is, in theory at least, a voluntary matter whether or not any advice offered by GMAG (HSE will be relying on GMAG for that) is followed.

In practice, however, failure to comply with GMAG's suggestions is almost certain to lead to prosecution under the Health and Safety at Work Act. Information leading to such actions is expected to come either from the HSE's 'intelligence network', particularly safety officers in laboratories or via GMAG which includes two assessors from the HSE. The presence of these assessors has already been persuasive on rare occasions when there was reluctance to meet GMAG's advice.

The Genetic Manipulation Regulations will not be the last official word on the subject in the UK. Already a governmental Select Committee on Science and Technology is in the process of looking at genetic manipulation. Meanwhile, Leo Abse, a member of parliament, has criticised the new HSE regulations as being totally inadequatc and providing no effective, enforceable control. Lastly, if the HSE considers that scientists are not complying with the suggestions of GMAG, it intends to incorporate the suggestions into an enforceable Approved Code under the Health and Safety at Work Act.

\section{Peter Newmark}

\section{Soviets plan 'a new space event'}

RECENT checks on the Salyut-6 space station, at present operating automatically, showed all systems working normally. According to Moscow radio "a new space event" is expected shortly, which is presumed to include at least one non-Russian cosmonaut. The Polish and East German candidates for the flight have now completed their training; for psychological reasons, however, it has not yet been decided who will be scheduled to make the flight. The Hungarian team has now completed the first two months of training "successfully".

The manned Interkosmos programme, with the personal participation of citizens of the Soviet Union's Comecon partners has, naturally, been hailed as a political triumph. "The fraternal friendship and cooperation of the countries of the socialist community has gone beyond the limits of our planet and into the wide-open spaces of our universe", declared $\mathrm{Mr}$ Brezhnev.

Admittedly, there are some minor and unofficial doubts about the participation of the less influential member states. All have been promised a flight for one cosmonaut within the current series of tests. No timetable has been announced, but if the programme is to be completed before the next solar maximum, it seems not improbable that the Mongolian and Cuban representatives, for example, will have to be content with a short space-ride rather than a record-breaking epic.

Commenting recently on the future development of space stations, Yurii Zaitsev, head of the Soviet Space Research Institute, noted that in the opinion of Konstantin Feokistov, himself a cosmonaut, the present generation of orbital stations have so many instruments aboard that it would be impracticable to build much bigger stations than Salyut at present.

On the other hand, Zaitsev added, "in future it may become more practicable to build stations which will work for decades with some 20-30 cosmonauts working in shifts. And as a long term objective, $I$ could mention superlarge, multi-purpose space complexes meant for a crew of 100 or more".

Zaitsev's remark is not the only hint that the Soviet space planners now preparing more seriously for more manned missions beyond the earth's orbit. Results from the Czech team, who have been processing the results of algae studies aboard Salyut-6, note that no genetic changes attributable to weightlessness have so far been ascertained-a fact which "bodes well for man's extended flights in outer space".

And looking still further ahead to permanent lunar colonies, the latest issue of Kosmicheskaya Biologiya $i$ Aviakosmicheskaya Meditsina reports that plants such as wheat, turnips, beetroot and radishes, grown in a quasilunar photocycle of 15 days light, 15 days dark gave a satisfactory yield of oxygen and food products, although the latter were somewhat less from than the "earth-cycle" control specimens. Since seeds from one generation of plants germinated to provide the next generation, the prospects for a selfsustaining colony (without the expensive imports of seeds characteristic of previous models) are felt to be extremely promising.

Vera Rich 